\title{
Brief communications
}

\section{Effect of celite and kaolin on activated clotting time in the presence of aprotinin: Activated clotting time is reduced by binding of aprotinin to kaolin}

\author{
W. Dietrich, MD, and M. Jochum, $\mathrm{PhD}$, \\ Munich, Germany
}

Prolongation of the activated clotting time (ACT) by celite is a widely known effect of high-dose aprotinin application in cardiac surgery. ${ }^{1}$ In contrast, kaolin-activated $\mathrm{ACT}$ is not influenced by aprotinin. ${ }^{2}$ In a recent publication in this Journal, Wang and associates ${ }^{3}$ speculated that celite may "artificially" prolong ACT, thus rendering the control of anticoagulation by the celite ACT unreliable. This may lead to underheparinization of the patient. ${ }^{4}$ The possibility of insufficient anticoagulation was even blamed for an increase of the prevalence of myocardial ischemia or infarction during and after cardiac operations. $^{5}$

To investigate the influence of either celite or kaolin on the ACT in the presence of aprotinin, we performed the following study. After obtaining informed consent, we took blood samples to determine the plasma aprotinin concentrations in 11 patients who were treated with high-dose aprotinin during cardiac operations (total dosage $6 \times 10^{6} \mathrm{KIU}$ ). All patients received mucosa heparin in a dose of $375 \mathrm{U} / \mathrm{kg}$ for cardiopulmonary bypass (CPB). The samples consisted of $2 \mathrm{ml}$ of citrate-treated blood rotated for 10 minutes in either celite or kaolin test tubes in an automated ACT device (Hemochron, International Technidyne Corp, Edison, N.J.). Thereafter the celiteand kaolin-activated blood samples and an additional sample, which was not in contact with an activator, were centrifuged at $3000 \mathrm{~g}$ for 10 minutes and the supernatant plasma was frozen immediately. In these plasma samples aprotinin concentrations were measured by a specific enzyme-linked immunosorbent assay test. ${ }^{6}$ Measurements were performed either before or 30 minutes after the

From the Department of Anesthesiology, German Heart Center Munich, Division of Clinical Biochemistry, Department of Surgery, LM University, Munich, Germany.

J THORAC CARDIOVASC SURG 1995;109:177-8

Copyright (C) 1995 by Mosby-Year Book, Inc.

$0022-5223 / 95 \$ 3.00+0 \quad \mathbf{1 2 / 8} / \mathbf{5 5 9 9 7}$ onset of CPB. Data were compared with the paired Student's $t$ test with the Bonferroni correction.

Results are given in Fig. 1. Aprotinin concentrations in plasma from celite tubes were slightly lower than those in plasma without contact with an activator $(134 \pm 49$ versus $88 \pm 39 \mathrm{KIU} / \mathrm{ml}, p<0.05)$. In contrast, in the kaolin tubes, aprotinin was considerably diminished up to $6.7 \pm$ 4.6 KIU $/ \mathrm{ml}$ (lower detection limit of the assay: 1 to 5 $\mathrm{KIU} / \mathrm{ml})$.

In the neutral $\mathrm{pH}$ range, aprotinin is a highly positively charged molecule, whereas kaolin is more negatively charged than celite. In our experiment, aprotinin was nearly undetectable in the plasma that was in contact with kaolin. These results suggest that the positively charged aprotinin is bound to kaolin in the test tube. Therefore, aprotinin cannot inhibit contact-phase activation that takes place during rotation in the test tube.

As a result, there is no "artificial" prolongation of the celite ACT. The celite ACT is prolonged because of the inhibition of the contact-phase activation in the presence of aprotinin. In contrast, the kaolin ACT is "artificially" shortened because aprotinin is bound to kaolin in the test tube and, consequently, contact phase activation is not inhibited in these samples. Thus only celite ACT mirrors this contact-phase inhibition by aprotinin. The question remains, however, whether the inhibition of the contact phase, which occurs during $\mathrm{CPB},{ }^{8}$ is of clinical relevance. On the basis of our previous results, ${ }^{9}$ we are convinced that inhibition of the contact-phase activation during CPB by aprotinin leads to a synergistic effect to heparin on anticoagulation and, finally, to better preserved hemostasis during CPB. Therefore inhibition of contact-phase activation seems to be of clinical relevance.

Until this question is finally answered, it seems advisable to measure ACT during CPB with both celite and kaolin tubes. Because kaolin excludes the anticoagulatory effect of aprotinin, standard accepted heparin levels may be better monitored with the kaolin ACT. For safety reasons, heparinization (which is not synonymous with anticoagulation, especially in the presence of aprotinin) may be based on the kaolin time, though our experience ${ }^{10}$ suggests that the celite ACT is reliable and does not lead to underheparinization during cardiac operations.

\section{REFERENCES}

1. Dietrich W, Spannagl M, Jochum M, et al. Influence of high-dose aprotinin treatment on blood loss and 


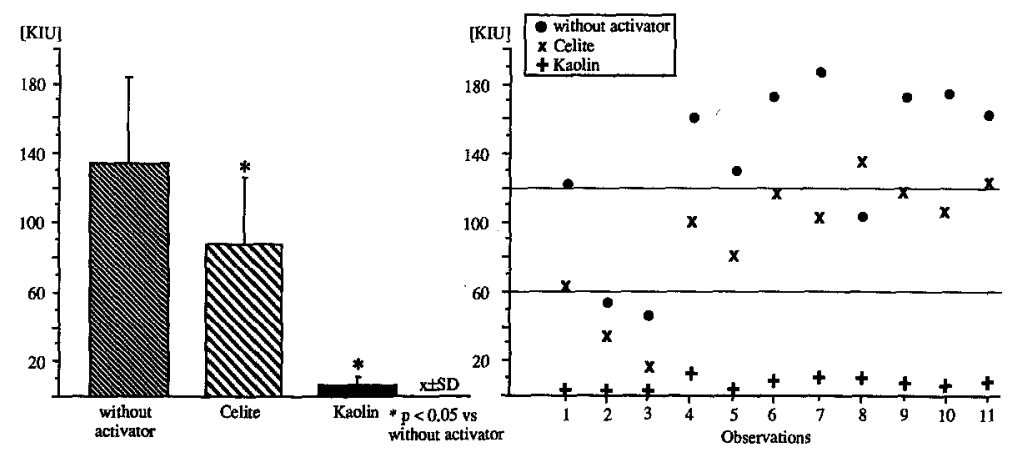

Fig. 1. Aprotinin plasma concentrations. The left part of the figure shows aprotinin concentrations (mean \pm standard deviation) in plasma samples directly drawn from the patient and in specimens that were rotated for 10 minutes in either celite or kaolin test tubes. The right side shows the individual measurements for each patient. Aprotinin was almost undetectable in the kaolin tubes, which indicates a binding of aprotinin to kaolin.

coagulation pattern in patients undergoing myocardial revascularization. Anesthesiology 1990;73:111926.

2. Wendel HP, Heller W, Gallimore MJ, Bantel H, Müller-Beissenhirtz $\mathbf{H}$, Hoffmeister HE. The prolonged activated clotting time (ACT) with aprotinin depends on the type of activator used for measurement. Blood Coagul Fibrinolysis 1993;4:41-5.

3. Wang JS, Lin CY, Hung WT, Thisted RA, Karp RB. In vitro effects of aprotinin on activated clotting time measured with different activators. J THORAC CARDIOVASC SURG 1992;104:1135-40.

4. Hunt BJ, Segal HC, Yacoub M. Guidelines for monitoring heparin by the activated clotting time when aprotinin is used during cardiopulmonary bypass [Letter]. J Thorac Cardiovasc SuRg 1992;104:211-2.

5. Cosgrove DM, Heric B, Lytle BW, et al. Aprotinin therapy for reoperative myocardial revascularization a placebo-controlled study. Ann Thorac Surg 1992;54: 1031-8.

6. Müller-Esterl W, Oettl A, Truscheit E, Fritz H. Monitoring of aprotinin plasma levels by an enzymelinked immunosorbent assay (ELISA). Fresenius $\mathrm{Z}$ Anal Chem 1984;317:718.

7. Fritz $\mathrm{H}$, Wunderer $\mathrm{G}$. Biochemistry and applications of aprotinin, the kallikrein inhibitor from bovine organs. Arzneim Forsch/Drug Res 1983;33:479-94.

8. Wachtfogel YT, Kucich U, Hack CE, et al. Aprotinin inhibits the contact, neutrophil, and platelet activation systems during simulated extracorporeal perfusion. J Thorac Cardiovasc Surg 1993;106:1-10.

9. Dietrich W, Richter JA, Schramm W, Spannagl M. What is the mechanism of action of aprotinin? Reply. Anesthesiology 1991;75:378-9.

10. Dietrich W, Barankay A, Hahnel C, Richter JA. High-dose aprotinin in cardiac surgery: three years' experience in 1,784 patients. J Cardiothorac Vasc Anesth 1992;6:324-7.

\section{Use of an intraluminal shunt to repair a coronary bypass graft injury during resternotomy}

T. Carrel, MD, M. Pasic, MD, U. Niederhäuser, MD, and M. Turina, MD, Zurich, Switzerland

In recent years, there has been an increase in the number of patients who are subjected to second cardiac procedures for correction of congenital heart defects, valve problems, and repeat coronary artery revascularization. Catastrophic hemorrhage is a rare complication that may occur while the sternum is being reopened. The most frequent causes include tears of the right ventricle and lesions of previous coronary bypass grafts; less common are bleeding from ascending aortic aneurysms or tears in the right atrium.

In 1985, a 66-year old patient had undergone an aortic valve replacement with a Capentier-Edwards bioprosthesis (Baxter Healthcare Corp., Edwards Div., Santa Ana, Calif.) and a saphenous vein graft to the circumflex artery with jump anastomoses to an intermediate branch, the first diagonal branch, and the left anterior descending artery. Postoperative recovery was uneventful, and the patient felt well until 1992. At this time, the patient reported having exertional dyspnea and increasing weariness. A cardiologic examination was performed and transthoracic echocardiography demonstrated degeneration of the bioprosthesis, resulting in moderate aortic stenosis (mean systolic gradient $45 \mathrm{~mm} \mathrm{Hg}$, peak-to-peak gradient $70 \mathrm{~mm} \mathrm{Hg}$, and a valve opening area of $0.8 \mathrm{~cm}^{2}$ ). Left ventricular function was severely depressed with an ejection fraction of 0.26 . At coronary angiography, each coronary-saphenous vein anastomosis was patent but

From the Clinic for Cardiovascular Surgery, University Hospital, Zurich, Switzerland.

J THORAC CARdiovasc Surg 1995;109:178-9

Copyright (C) 1995 by Mosby-Year Book, Inc.

$0022-5223 / 95 \$ 3.00+0 \quad \mathbf{1 2 / 8 / 5 5 5 4 2}$ 